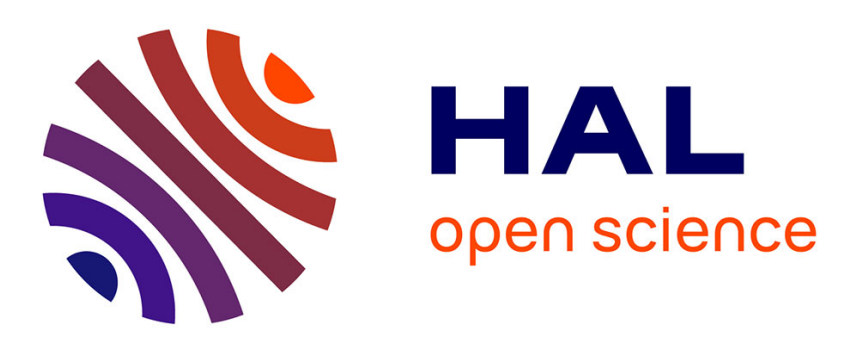

\title{
Analysis of Dependency Evaluation Models for e-Health Services
}

Haider Mshali, Tayeb Lemlouma, Damien Magoni

\section{To cite this version:}

Haider Mshali, Tayeb Lemlouma, Damien Magoni. Analysis of Dependency Evaluation Models for e-Health Services. IEEE Global Communications Conference, Dec 2014, Austin, TX, United States. pp.2429-2435, 10.1109/GLOCOM.2014.7037172 . hal-01058185

\section{HAL Id: hal-01058185 \\ https://hal.science/hal-01058185}

Submitted on 3 Nov 2017

HAL is a multi-disciplinary open access archive for the deposit and dissemination of scientific research documents, whether they are published or not. The documents may come from teaching and research institutions in France or abroad, or from public or private research centers.
L'archive ouverte pluridisciplinaire HAL, est destinée au dépôt et à la diffusion de documents scientifiques de niveau recherche, publiés ou non, émanant des établissements d'enseignement et de recherche français ou étrangers, des laboratoires publics ou privés. 


\section{Analysis of Dependency Evaluation Models for eHealth Services}

\author{
Haider Mshali \\ University of Bordeaux-LaBRI \\ Talence, France \\ hayder.mshali@univ-rennes1.fr
}

\author{
Tayeb Lemlouma \\ University of Rennes 1-IRISA \\ Lannion, France \\ Tayeb.Lemlouma@irisa.fr
}

\author{
Damien Magoni \\ University of Bordeaux-LaBRI \\ Talence, France \\ magoni@labri.fr
}

\begin{abstract}
This work focuses on the evaluation of the need and help required by elderly and dependent persons. We study the most widely used evaluation models in the health domain. We propose a new algorithm to assess and compare the performance of these models and the possibility to use them in future eHealth systems and platforms. The objective is to shed some light on the weakness of existing models and to gain a better knowledge about the context of persons in order to provide them with eHealth services that match their context and meet their needs.
\end{abstract}

Keywords-Dependency; ADL; AGGIR; SMAF; eHealth; Services

\section{INTRODUCTION}

The elderly dependency ratios are rising according to United Nations' projections. In 2050, the dependency ratio of people, aged 65 years or more, will approximate $54 \%$ in more developed regions [1]. This increase of dependency requires improving healthcare and the quality of services provided in eHealth domain. Provided services should meet the real needs of persons in real time. Dependency evaluation models are used to identify these needs of assistance and services. Continuous monitoring of the person's ability to achieve basic activities becomes an urgent necessity. This monitoring allows detecting any changes related to the needs and requirements by indicating any decline or improvement of the person's health state. Most of the existing evaluation models used in the monitoring domain (e.g. AGGIR, SMAF and FIM) are performed manually and by clinical staff. We observe also that in these models, in spite of considering the same daily activities for the same purpose, they unfortunately lead to different dependency evaluations. The objective that we target is to provide eHealth services based on an automatic and homogeneous evaluation of the person's needs in terms of healthcare. To do so, we believe that smart eHealth platforms and systems have to gain a better knowledge about the context of monitored persons. This will provide persons with contextaware services i.e. adapted and personalized services that match their required needs and assistance. This work can be seen as a first step to provide context-aware services for smart systems and platforms such as homes, cities and hospitals (Fig. 1). We consider the monitored person's context by studying the exiting tools used by professionals in the health domain. In this paper, we focus on the needs of healthcare services for dependent persons. We study some of the most famous models used in geriatrics field to evaluate people's dependency. We consider the AGGIR model [2] used in France and the SMAF model [3] used in Canada. We discuss the compatibility between them including the considered person's activities (items), results and classification. We shed some light on the weakness of dependency models used in the health domain, which will help to improve the consideration of the person's context and focus on the main activities to be monitored.

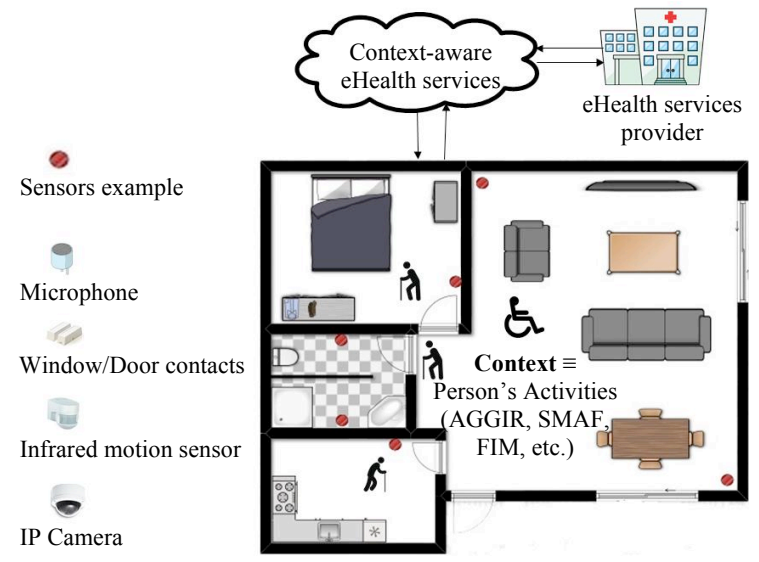

Fig. 1. Overall architecture of context-aware eHealth services at home

\section{DEPENDENCY EVAluation Models}

The person's dependency can be defined as the ability of a person to achieve elementary tasks of daily living without the help or stimulation of a third party [4]. To assess this ability, many tools and methods have been developed. They include the determination of what is a basic activity of daily living, (called ADL) and the methodology of assessment to evaluate each activity. Most of the existing methods use the definition of the ADL as introduced by Katz [5], and the instrumental activity of daily living IADL of Lawton [6]. ADL refers to the routine and basic tasks performed by persons every day, such as eating and washing etc. IADL refers to the necessary tasks to live in the community (such as medication use and budgeting) which are usually lost before the ADL. The concept of group is usually used in the evaluation methods for classifying persons based on: needs, assistance, costs, diagnosis, etc. This classification tries to aggregate people having the same characteristics and who need approximately the same level of services and resources. For instance, using 
the called iso-resources group [2], iso-profile SMAF [7], FIMFRG [8] and diagnosis related groups (DRG) [9]. In practice, these evaluation models are used to guide the health institution to make right decisions while providing healthcare with or without monitoring. Most of these models are performed manually. This makes them exposed to human errors and lacking immediate alerts in case of any change or decline of the health status of the person. In the context of eHealth services and smart home/city environments, the determination of the most important daily activities that directly affect the lives of the elderly is of high concern. It is the essence and basis of automatic evaluation and monitoring. The continuous monitoring of these activities helps to reveal the person's real needs and allows providing assistance and services required immediately.

Many previous researches have been done in order to propose new systems and platforms that ensure eHealth services $[10][11][12]$. We believe that in order to provide health professionals with flexible, reliable and smart monitoring systems, a strong link should be kept between the existing medical tools and data on the one hand and new proposed approaches on the other hand. This link will help to: (a) put the light on the drawbacks of existing medical methods, (b) propose required improvements and (c) make easier the integration of the new proposed eHealth systems into health institutions (e.g. using existing patient's record, historic, etc.). In this work, we study the overlaps and differences between the most important models in the domain of health dependency evaluations. Table I compares the difference between the models most used today in the health domain for people dependency evaluation. Items are related to activities used in the models while the classification function returns the whole evaluation of the person based on the individual qualification and scores. Profiles concern the losses of autonomy of persons. Profiles give a detailed classification while groups and categories reduce this classification into common sets. A detailed description of the AGGIR and SMAF models is discussed in the next sections.

TABLE I. COMPARISON BETWEEN DEPENDENCY MODELS

\begin{tabular}{|l|l|l|l|}
\hline \multicolumn{1}{|c|}{ Models } & \multicolumn{1}{|c|}{ AGGIR } & \multicolumn{1}{c|}{ SMAF } & \multicolumn{1}{c|}{ FIM } \\
\hline Items & 17 & 29 & 18 \\
\hline Classification function & 8 & 29 & 18 \\
\hline Qualification item & $\begin{array}{l}4(\mathrm{~S}, \mathrm{~T}, \mathrm{U} \\
\text { and C) }\end{array}$ & $\begin{array}{l}4 \text { or } 5(0,-0.5,-1, \\
-2,-3)\end{array}$ & 1 to 7 \\
\hline Scoring criteria & $\begin{array}{l}3(\mathrm{~A}, \mathrm{~B} \text { and } \\
\mathrm{C})\end{array}$ & $\begin{array}{l}4 \text { or } 5(0,-0.5,-1, \\
-2,-3)\end{array}$ & 1 to 7 \\
\hline $\begin{array}{l}\text { Minimum Level of } \\
\text { dependency }\end{array}$ & $<2000$ & 9.33 & 126 \\
\hline $\begin{array}{l}\text { Maximum Level } \\
\text { dependency }\end{array}$ & $<=4380$ & -87 & 18 \\
\hline Number of Profiles & 13 & 14 & $/$ \\
\hline $\begin{array}{l}\text { Classification group or } \\
\text { categories }\end{array}$ & 6 groups & 4 categories & $\begin{array}{l}\text { FIM-FRG version } \\
2.0,21 \text { categories } \\
\text { subdivided into } 67 \\
\text { FRGs }\end{array}$ \\
\hline Achieve manually & Yes & Yes & Yes \\
\hline
\end{tabular}

\section{A. Description of the SMAF Model}

Functional Autonomy Measurement System (SMAF) is a clinical rating scale that measures the functional autonomy of elderly patients [3]. The SMAF used in order to rehabilitate the individual by provide appropriate care and services and assessing needs to alleviate the disabilities in elderly people [13][14]. Handicap is the relation between disability and the available social or material resources, taken into account to alleviate rate of disability. There are 29-items rating scale used to evaluates person's dependency, and access to the available resources that may offset for the disabilities, as well the stability of resources. These items are included in the five aspects of functional abilities: activities of daily living ADL (7 items), mobility (6 items), communication (3 items), mental functions (5 items), and instrumental activities of daily living IADL (8 items). The SMAF model is administrated manually by a health professional. The raters use all available information to do the rating. Dependency is evaluated by using a scale for each item with a 5-point rating scale: $0,-0.5,-1,-2$ and -3 . Items are evaluated using a function scoring: 0 : independently, -0.5 : independently but with difficulty, -1 : needs supervision or stimulation,-2: needs help,-3: dependent. 10 of the SMAF items are measured only using 4-point rating scale, i.e. $0,-1,-2$ and -3 such as Urinary, Bowel, Vision, etc. The disability from autonomy to dependency is identified with a maximum negative scores of -87 , a higher disability score indicates a higher level of dependence. The handicap assessment is necessary to overcome the disability score. If the social resources are accessible to compensate for the disability, the handicap score is zero; otherwise the handicap score equals the disability score [14][15].

SMAF has been developed in [7] to include 14 profiles of dependency patterns called iso-SMAF profiles. Each profile is associated with a specific amount of nursing, support services, supervision needed and the costs of services, based on the disabilities of their patient groups. In SMAF, the first profile (profile 1) represents the persons that are autonomous while the last profile (profile 14) represents completely dependent persons. These profiles based on the results of the information of all the 29 items. From the first to the last iso-SMAF profiles, the mean level of disability increases from 9.4 to 73.8 out of a potential of 87 . These 14 iso-SMAF profiles can be divided into 4 categories: 1- includes subjects who are autonomous with some IADL required supervision and help (profiles 1, 2, and 3); 2- includes subjects who show mobility functions disabilities (profiles 4, 6, and 9); 3- includes subjects who show mental disabilities (profiles 5, 7,8, and 10); and 4- shows the lowest level of autonomy i.e. dependency in all ADL activities (profiles 11, 12, 13, and 14) [7][16][17]. Table II briefly illustrates the association between profiles, disability score and classification group of iso-SMAF profiles.

\section{B. Description of the AGGIR Model}

Autonomy Gerontology Iso-Resources Group (AGGIR) is an evaluation dependency model used in France. AGGIR uses a complex algorithm to calculate the person's dependency. This model considers 17 items describing the activities of daily living. 10 discriminated items have been identified in this model, and 8 of them are really used in the classification of the 
TABLE II. ASSOCIATION BETWEEN PROFILES, DISABILITY SCORE AND CLASSIFICATION GROUP IN ISO-SMAF PROFILES

\begin{tabular}{|l|l|l|l|l|l|}
\hline $\begin{array}{l}\text { Number } \\
\text { of Profiles }\end{array}$ & $\begin{array}{l}\text { Disability } \\
\text { score } / \mathbf{8 7}\end{array}$ & Category & $\begin{array}{l}\text { Number } \\
\text { of Profiles }\end{array}$ & $\begin{array}{l}\text { Disability } \\
\text { score } / 87\end{array}$ & Category \\
\hline 1 & -9.33 & 1 & 8 & -42.24 & 3 \\
\hline 2 & -13.23 & 1 & 9 & -48.15 & 2 \\
\hline 3 & -19.76 & 1 & 10 & -53.02 & 3 \\
\hline 4 & -23.69 & 2 & 11 & -58.47 & 4 \\
\hline 5 & -28.54 & 3 & 12 & -58.71 & 4 \\
\hline 6 & -32.04 & 2 & 13 & -64.98 & 4 \\
\hline 7 & -39.19 & 3 & 14 & -73.77 & 4 \\
\hline
\end{tabular}

dependent persons, which in turn creates 13 profile ranks and 6 groups. Like SMAF, FIM and other dependency evaluation models, the AGGIR evaluation is achieved manually by a medical staff. The 13 profile ranks refer to a decline in autonomy of dependent persons. The 6 GIR groups, reduce the number of profiles and address the needs of assistance. The GIR algorithm computes the iso-resource group number (1 to 6) based on a predefined association between the profile ranks and groups (Table III). The first group (GIR 1) represents the persons that are completely dependent while the last group (GIR 6) represents autonomous persons. To identify a person's profile rank, the model uses 8 classification functions that compute the classification scores. The person is classified as belonging to the profile rank for which he/she has the highest classification score. Scores are tested in a sequential order using the classification functions from $S_{1}$ to $S_{8}$ (Table III). Classification functions are defined as: $\mathrm{S}_{1}=\sum_{k=1}^{0} w_{i k}$ where, $S_{i}$ the score of the $i$ th function; $\mathrm{w}_{i j}$ is the weight for the $j^{\prime}$ th variable modality which can be $A, B$ or $C$ [4]. In AGGIR, each item is qualified using 4 adverbs: Spontaneously (S), Completely/Totally (T), Usually (U) and Correctly (C). According to a logical condition involving these adverbs, the activity is evaluated with the modalities: $A, B$ or $C$. For instance, a given activity is evaluated with the modality $A$, if the person can achieve the activity with the following condition: $S \wedge T \wedge C \wedge U[4]$.

TABLE III. ASSOCIATION BETWEEN PROFILE RANKS, CLASSIFICATION SCORES GIR

\begin{tabular}{|c|c|c|}
\hline Profile Ranks & Score Condition & GIR \\
\hline 1 & $\mathrm{~S}_{1} \geq 4380$ & 1 \\
\hline 2 & $4140 \leq \mathrm{S}_{1}<4380$ & \\
3 & $3390 \leq \mathrm{S}_{1}<4140$ & 2 \\
4 & $\mathrm{~S}_{2} \geq 2016$ & \\
5 & $\mathrm{~S} 3 \geq_{1} 700$ & \\
6 & $1432 \leq \mathrm{S}_{3}<1700$ & \\
7 & $\mathrm{~S}_{4} \geq 2400$ & \\
\hline 8 & $\mathrm{~S}_{5} \geq 1200$ & 3 \\
9 & $\mathrm{~S}_{6} \geq 800$ & \\
\hline 10 & $\mathrm{~S}_{7} \geq 650$ & 4 \\
11 & $\mathrm{~S}_{8} \geq 4000$ & \\
\hline 12 & $2000 \leq \mathrm{S}_{8}<4000$ & 5 \\
\hline 13 & $\mathrm{~S}_{8}<2000$ & 6 \\
\hline
\end{tabular}

Table IV presents the different weights of the different variable modalities regarding $S_{1}$ and $S_{2}$ functions. As example to compute the evaluation regarding to this model, let us consider a person with the following evaluation: Coherence $=C$, Orientation $=C, \quad$ Hygiene $=C, \quad$ Dressing $=B, \quad$ Eating $=B$,
Elimination $=B$, Transfers $=A$ and Interior Moving $=B$. We have $S_{1}=\sum_{k=1}^{8} w_{1 k}=3324$ and $S_{2}=\sum_{k=1}^{8} w_{2 k}=2732$ (Table IV). To identify the profile rank, the score conditions are tested first with the $S_{1}$ score, if there is no satisfied condition, the score is then tested with $S_{2}$ and so forth until the last condition of $S_{8}$ $\left(S_{8}<2000\right)$. Here, the score of $S_{1}(3324)$ does not satisfy the $S_{1}$ score conditions (Table III). However, the score of $S_{2}(2732)$ satisfies the $S_{2} \geq 2016$ " condition (Table III). Hence, the person's profile rank is 4 and his iso-resource group is 2 .

TABLE IV. WEIGHTS OF THE CLASSIFICATION FUNCTIONS $\mathrm{S}_{1}$ AND $S_{2}$

\begin{tabular}{|c|c|c|c|l|c|c|c|}
\hline Activity & & $\mathbf{W}_{\mathbf{1 i}}$ & $\mathbf{W}_{\mathbf{2 i}}$ & Activity & & $\mathbf{W}_{\mathbf{1 i}}$ & $\mathbf{W}_{\mathbf{2 i}}$ \\
\hline Coherence & C & 2000 & 1500 & Eating & $\mathrm{C}$ & 60 & 60 \\
\hline & $\mathrm{B}$ & 0 & 320 & & $\mathrm{~B}$ & 20 & 0 \\
\hline & $\mathrm{A}$ & 0 & 0 & & $\mathrm{~A}$ & 0 & 0 \\
\hline Orientation & $\mathrm{C}$ & 1200 & 1200 & Elimination & $\mathrm{C}$ & 100 & 100 \\
\hline & $\mathrm{B}$ & 0 & 120 & & $\mathrm{~B}$ & 16 & 16 \\
\hline & $\mathrm{A}$ & 0 & 0 & & $\mathrm{~A}$ & 0 & 0 \\
\hline Hygiene & $\mathrm{C}$ & 40 & 40 & Transfers & $\mathrm{C}$ & 800 & 800 \\
\hline & $\mathrm{B}$ & 16 & 16 & & $\mathrm{~B}$ & 120 & 120 \\
\hline & $\mathrm{A}$ & 0 & 0 & & $\mathrm{~A}$ & 0 & 0 \\
\hline Dressing & $\mathrm{C}$ & 40 & 40 & Int. Moving & $\mathrm{C}$ & 200 & -80 \\
\hline & $\mathrm{B}$ & 16 & 16 & & $\mathrm{~B}$ & 32 & -40 \\
\hline & $\mathrm{A}$ & 0 & 0 & & $\mathrm{~A}$ & 0 & 0 \\
\hline
\end{tabular}

Table $\mathrm{V}$ shows the evaluation of activities using the SMAF scores and the AGGIR modalities.

\section{Methodology}

In order to study how dependency situations are handled in existing models used in the healthcare domain, we have performed simulations for all the possible dependency situations using SMAF and AGGIR models. We have handled a huge amount of data coming from twenty trillions $\left(5^{19} .4^{10}\right)$ possible evaluations in SMAF and more than six thousands $\left(3^{8}\right)$ possible evaluations in AGGIR. Each processed evaluation represents a person with a certain situation of dependency. A given situation is represented by values associated to all the items defined in the used model. In our simulations, we perform an aggregation and a matching between SMAF and AGGIR items which are referring to similar activities. We have identified thirteen (13) items from SMAF and all the items (8) from the AGGIR model. Fig. 2 shows an example of this matching.

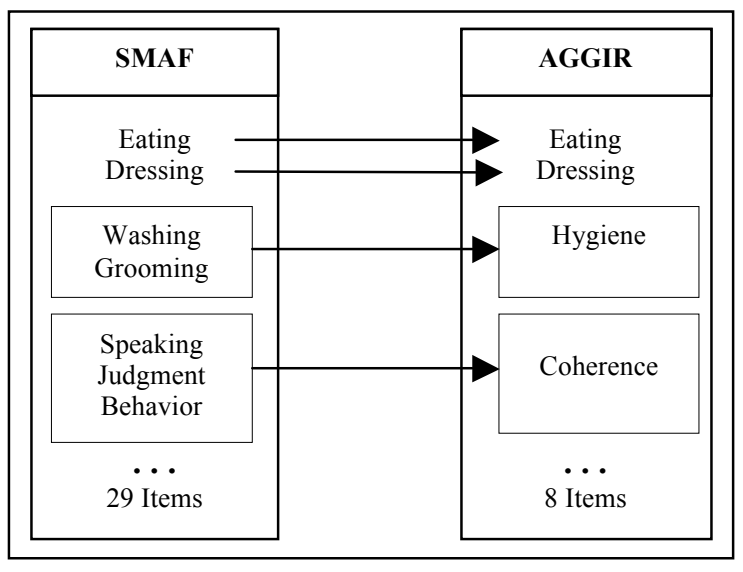

Fig. 2. Proposed Matching of Items between Dependency Models 
TABLE V. ITEMS EVALUATION WITH SMAF AND AGGIR METHODS

\begin{tabular}{|c|c|c|c|c|}
\hline & SMAF & AGGIR & $\begin{array}{c}\text { AGGIR } \\
\text { Modalities }\end{array}$ & $\begin{array}{c}\text { SMAF } \\
\text { Modalities }\end{array}$ \\
\hline \multirow{7}{*}{$\overrightarrow{8}$} & 1. Eating & 1. Eating & $3(\mathrm{~A}, \mathrm{~B}$ and $\mathrm{C})$ & $5(0,-0.5,-1,-2,-3)$ \\
\hline & 2. Dressing & 2. Dressing & $3(\mathrm{~A}, \mathrm{~B}$ and $\mathrm{C})$ & $5(0,-0.5,-1,-2,-3)$ \\
\hline & 3. Washing & \multirow[t]{2}{*}{ 3. Hygiene } & \multirow[t]{2}{*}{$3(\mathrm{~A}, \mathrm{~B}$ and $\mathrm{C})$} & $5(0,-0.5,-1,-2,-3)$ \\
\hline & 4. Grooming & & & $5(0,-0.5,-1,-2,-3)$ \\
\hline & 5. Urinary function & \multirow{3}{*}{$\begin{array}{l}4 . \\
\text { Elimination }\end{array}$} & \multirow[t]{3}{*}{$3(\mathrm{~A}, \mathrm{~B}$ and $\mathrm{C})$} & $4(0,-1,-2,-3)$ \\
\hline & 6. Bowel function & & & $4(0,-1,-2,-3)$ \\
\hline & 7. Toileting & & & $5(0,-0.5,-1,-2,-3)$ \\
\hline \multirow{6}{*}{ 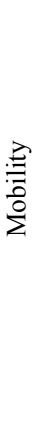 } & 1. Transfers & 1. Transfers & $3(\mathrm{~A}, \mathrm{~B}$ and $\mathrm{C})$ & $5(0,-0.5,-1,-2,-3)$ \\
\hline & 2. Walking inside & $\begin{array}{l}\text { 2. Internal } \\
\text { Moving }\end{array}$ & $3(\mathrm{~A}, \mathrm{~B}$ and $\mathrm{C})$ & $5(0,-0.5,-1,-2,-3)$ \\
\hline & 3. Walking outside & & & $5(0,-0.5,-1,-2,-3)$ \\
\hline & $\begin{array}{l}\text { 4. Donning } \\
\text { prosthesis or } \\
\text { orthotic }\end{array}$ & & & $5(0,-0.5,-1,-2,-3)$ \\
\hline & $\begin{array}{l}\text { 5. Propelling a } \\
\text { wheelchair }\end{array}$ & & & $5(0,-0.5,-1,-2,-3)$ \\
\hline & 6. Negotiating stairs & & & $5(0,-0.5,-1,-2,-3)$ \\
\hline \multirow{3}{*}{$\sum_{0}^{\dot{0}}$} & 1. Vision & & & $4(0,-1,-2,-3)$ \\
\hline & 2. Hearing & & & $4(0,-1,-2,-3)$ \\
\hline & 3. Speaking & \multirow{3}{*}{$\begin{array}{l}2 . \\
\text { Coherence }\end{array}$} & \multirow[t]{3}{*}{$3(\mathrm{~A}, \mathrm{~B}$ and $\mathrm{C})$} & $4(0,-1,-2,-3)$ \\
\hline \multirow{5}{*}{ 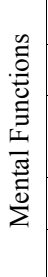 } & 1. Behavior & & & $4(0,-1,-2,-3)$ \\
\hline & 2. Judgment & & & $4(0,-1,-2,-3)$ \\
\hline & 3. Orientation & $\begin{array}{l}1 . \\
\text { Orientation }\end{array}$ & $3(\mathrm{~A}, \mathrm{~B}$ and $\mathrm{C})$ & $4(0,-1,-2,-3)$ \\
\hline & 4. Memory & & & $4(0,-1,-2,-3)$ \\
\hline & 5. Comprehension & & & $4(0,-1,-2,-3)$ \\
\hline \multirow{8}{*}{$\vec{\Xi}$} & 1. Housekeeping & & & $5(0,-0.5,-1,-2,-3)$ \\
\hline & 2. Meal preparation & & & $5(0,-0.5,-1,-2,-3)$ \\
\hline & 3. Shopping & & & $5(0,-0.5,-1,-2,-3)$ \\
\hline & 4. Laundry & & & $5(0,-0.5,-1,-2,-3)$ \\
\hline & 5. Telephone & & & $5(0,-0.5,-1,-2,-3)$ \\
\hline & 6. Transportation & & & $5(0,-0.5,-1,-2,-3)$ \\
\hline & 7. Medication use & & & $5(0,-0.5,-1,-2,-3)$ \\
\hline & 8. Budgeting & & & $5(0,-0.5,-1,-2,-3)$ \\
\hline
\end{tabular}

In our matching, we associate either one item of SMAF to one item of AGGIR (one-to-one) or several items of SMAF to one item of AGGIR (many-to-one). For instance, in the first case: eating in SMAF with scoring criteria, varying from -3 to 0 , corresponds with eating in AGGIR with scoring criteria: $A$, $B$ or $C$. For the second case, we perform the matching between SMAF and AGGIR items by using a specific rate ratio of the priority for each item. For instance, in the matching with the AGGIR's hygiene item $(H)$, we associate washing with a 0.70 ratio of priority and grooming with a 0.30 ratio of priority (i.e. $H=0.7$.Washing +0.3 .Grooming, see Fig. 2 and Table VI). The choice of these weights is because only some part of grooming's properties cares about cleaning in SMAF. In the SMAF model, the scoring of 0 refers to a full autonomy while 0.5 refers to autonomy with minor difficulties. Consequently, we associate 0 and -0.5 with the $A$ scoring of AGGIR. The SMAF scoring of -1 and -2 indicate an increased level of dependency so we associate it with $B$ in AGGIR. Finally, the maximum level of dependency is evaluated with -3 in SMAF and $C$ in AGGIR. Table VI illustrates those items' matching between SMAF and AGGIR. Notice that in the simple matching (one-to-one) we have the following associations: $-3 \rightarrow \mathrm{C},-2 \rightarrow \mathrm{B},-1 \rightarrow \mathrm{B},-0.5 \rightarrow \mathrm{A}, 0 \rightarrow \mathrm{A}$. For the many-to-one matching we use the following associations: $[-3,-2[\rightarrow \mathrm{C},[-2$ $,-1] \rightarrow \mathrm{B}, \mathrm{-1}, \mathrm{e}] \rightarrow \mathrm{A}$.

TABLE VI. MATCHING USED IN OUR PROPOSED ALGORITHM

\begin{tabular}{|c|c|c|c|}
\hline & $\begin{array}{l}\text { SMAF } \\
\text { items }\end{array}$ & $\begin{array}{l}\text { AGGIR } \\
\text { items }\end{array}$ & $\begin{array}{c}\text { Matching from SMAF item to } \\
\text { AGGIR item }\end{array}$ \\
\hline \multirow{7}{*}{$\stackrel{2}{8}$} & Eating & Eating & $\begin{array}{l}\text { Eating } \rightarrow \text { Eating: } \\
0 \rightarrow \mathrm{A},-0.5 \rightarrow \mathrm{A},-1 \rightarrow \mathrm{B},-2 \rightarrow \mathrm{B},-3 \rightarrow \mathrm{C}\end{array}$ \\
\hline & Dressing & Dressing & $\begin{array}{l}\text { Dressing } \rightarrow \text { Dressing: } \\
0 \rightarrow \mathrm{A},-0.5 \rightarrow \mathrm{A},-1 \rightarrow \mathrm{B},-2 \rightarrow \mathrm{B},-3 \rightarrow \mathrm{C}\end{array}$ \\
\hline & Washing & \multirow[t]{2}{*}{ Hygiene } & \multirow[b]{2}{*}{$\begin{array}{l}\text { (Washing } \epsilon\{0,-0.5,-1,-2,-3\} \\
\text { Grooming } \epsilon\{0,-0.5,-1,-2,-3\}) \\
\rightarrow \text { Hygiene } \epsilon\{\mathrm{A}, \mathrm{B}, \mathrm{C}\}: \\
H=0.7 . \text { Washing }+0.3 \text {.Grooming } \\
H \in[-3,-2[\rightarrow \text { Hygiene }=\mathrm{C} \\
H \in[-2,-1] \rightarrow \text { Hygiene }=\mathrm{B} \\
H \epsilon]-1,0] \rightarrow \text { Hygiene }=\mathrm{A}\end{array}$} \\
\hline & Grooming & & \\
\hline & $\begin{array}{l}\text { Urinary } \\
\text { function }\end{array}$ & \multirow[t]{3}{*}{ Elimination } & \multirow{3}{*}{$\begin{array}{l}\text { (Urinary } €\{0,-1,-2,-3\}, \text { Bowel } €\{0,- \\
1,-2,-3\} \text {, Toileting } €\{0,-0.5,-1,-2,- \\
3\}) \rightarrow \text { Elimination } €\{\mathrm{~A}, \mathrm{~B}, \mathrm{C}\}: \\
\mathrm{E}=0.4 \text {.Urinary }+0.4 \text {. Bowel }+0.2 \text {. } \\
\text { Toileting } \\
\mathrm{E} \in[-3,-2[\rightarrow \text { Elimination }=\mathrm{C} \\
\mathrm{E} \in[-2,-1] \rightarrow \text { Elimination }=\mathrm{B} \\
\mathrm{E} \in]-1,0] \rightarrow \text { Elimination }=\mathrm{A}\end{array}$} \\
\hline & $\begin{array}{l}\text { Bowel } \\
\text { function }\end{array}$ & & \\
\hline & Toileting & & \\
\hline \multirow{2}{*}{ 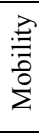 } & Transfers & Transfers & $\begin{array}{l}\text { Transfers } \rightarrow \text { Transfers: } \\
0 \rightarrow \mathrm{A},-0.5 \rightarrow \mathrm{A},-1 \rightarrow \mathrm{B},-2 \rightarrow \mathrm{B},-3 \rightarrow \mathrm{C}\end{array}$ \\
\hline & $\begin{array}{l}\text { Walking } \\
\text { inside }\end{array}$ & $\begin{array}{l}\text { Internal } \\
\text { Moving }\end{array}$ & $\begin{array}{l}\text { Walking inside } \rightarrow \text { Internal Moving } \\
0 \rightarrow A,-0.5 \rightarrow A,-1 \rightarrow B,-2 \rightarrow B,-3 \rightarrow C\end{array}$ \\
\hline$*$ & Speaking & \multirow[t]{3}{*}{ Coherence } & \multirow{3}{*}{$\begin{array}{l}\text { (Behavior } \epsilon\{0,-1,-2,-3\}, \text { Judgment } \\
\epsilon\{0,-1,-2,-3\}, \text { Speaking } \epsilon\{0,-1,-2,- \\
3\}) \rightarrow \text { Coherence } \epsilon\{\mathrm{A}, \mathrm{B}, \mathrm{C}\}: \\
C=0.5 \text {. Behavior }+0.3 \text {. Judgment }+ \\
0.2 \text {. Speaking } \\
C \in[-3,-2[\rightarrow \text { Coherence }=\mathrm{C} \\
C \in[-2,-1] \rightarrow \text { Coherence }=\mathrm{B} \\
C \in]-1,0] \rightarrow \text { Coherence }=\mathrm{A}\end{array}$} \\
\hline \multirow{3}{*}{ 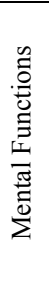 } & Behavior & & \\
\hline & Judgment & & \\
\hline & Orientation & Orientation & $\begin{array}{l}\text { Orientation } \rightarrow \text { Orientation } \\
0 \rightarrow \mathrm{A},-0.5 \rightarrow \mathrm{A},-1 \rightarrow \mathrm{B},-2 \rightarrow \mathrm{B},-3 \rightarrow \mathrm{C}\end{array}$ \\
\hline
\end{tabular}

\section{PROPOSED AlgORITHM}

In this section, we propose a new algorithm that evaluates all the possible situations related to the different persons' activities (ADL and IADL). We consider the 29 activities $\left(\mathrm{SM}_{1}\right.$ to $\mathrm{SM}_{29}$ ) presented in Table $\mathrm{V}$ with the different dependency evaluations using either the SMAF or the AGGIR model. Our matching method, discussed in Section III, was implemented in the Smaf2Aggir Matching function. The function uses the different associations between the SMAF scores and the AGGIR evaluations presented in Table VI. We compute the SMAF profiles (GetSMAFprofile), match 13 items from SMAF to all the 8 items $\left(A_{1}\right.$ to $\left.A_{8}\right)$ used in AGGIR and then compute 
the AGGIR scores (AggirScor). Our algorithm returns the $M$ matrix that gives the distribution of all the dependency evaluations using SMAF and AGGIR. Indeed, after each simulation's instance (see the inner loops), the $M$ matrix counts the instance into the right index of $M$ (i.e. $M[S M A F$ Profile, $G I R] \leftarrow M\left[S M A F \_\right.$Profile, $\left.G I R\right]+\delta$ with $\left.\delta=1\right)$.

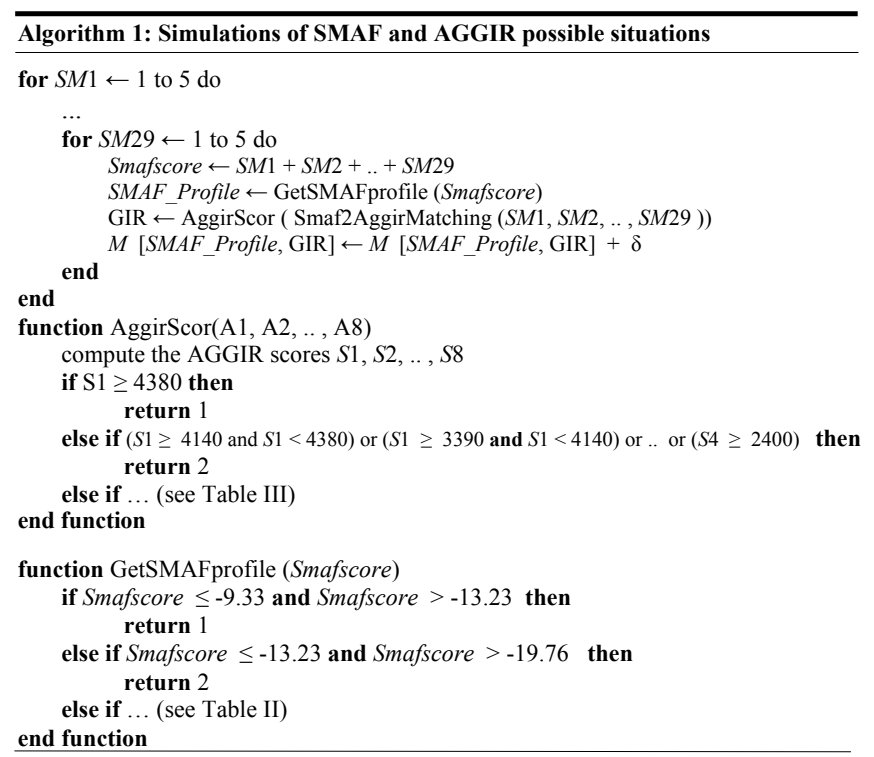

\section{EXPERIMENTATION AND RESULTS}

The execution time of the algorithm 1, as presented previously, takes a very long time. For a simulation of one million dependency situations, the running time was approximately 2.66 seconds under a DELL Precision M6700 with an Intel ${ }^{\circledR}$ Core TM $\mathrm{i} 7-3940 \mathrm{XM}, 3.20 \mathrm{GHz}$ processor with a RAM of 32 GB. This requires approximately 1.687 .826 years for the complete simulation (with the twenty trillions situations). In order to reduce this execution time required for performing all the simulations, we have split the twenty nine loops of our algorithm into two independent parts: the first part computes all of the possible scores (i.e., the $\delta$ value) of SMAF with the variables used in SMAF only; the second part computes the SMAF and AGGIR evaluations with the thirteen (13) variables (items) used in both of SMAF and AGGIR (see Table VI). The results of the first part (i.e. the possible values of $\delta$ ) are used in the second part. The running time of the first part was 1.35 hours (under the same simulation conditions) while the running time of the second part was 3.81 hours.

It is important to notice that the authors in [18] studied and compared the classification of persons' dependency using the two models AGGIR and SMAF. Their experimentations were done with a limited group of 207 persons. Unlike [18], we perform the simulation over all the possible dependency situations of people. We consider the evaluation scores for all the items (activities) used in both of SMAF and AGGIR models and achieve a complete correspondence between the items. Table VII shows the percentages of matching between iso-SMAF Profiles and AGGIR groups by applying our simulation (see Methodology Section). The results represent the $M$ matrix used in Algorithm 1 in the form of percentages.
TABLE VII. DISTRIBUTION PERCENTAGES BETWEEN SMAF AND AGGIR

\begin{tabular}{|c|c|c|c|c|c|c|}
\hline & $\mathrm{GIR}_{1}$ & $\mathrm{GIR}_{2}$ & $\mathrm{GIR}_{3}$ & $\mathrm{GIR}_{4}$ & GIR $_{5}$ & $\mathrm{GIR}_{6}$ \\
\hline $\mathbf{P}_{1}$ & 0 & 0.029 & 0.166 & 19.561 & 43.300 & 36.943 \\
\hline $\mathbf{P}_{2}$ & 0 & 0.653 & 3.047 & 40.587 & 38.199 & 17.514 \\
\hline $\mathbf{P}_{3}$ & 0 & 2.097 & 8.511 & 49.341 & 30.064 & 9.987 \\
\hline $\mathbf{P}_{4}$ & $1.10^{-10}$ & 5.650 & 18.482 & 51.089 & 19.957 & 4.822 \\
\hline $\mathbf{P}_{5}$ & $6.10^{-8}$ & 10.279 & 27.651 & 46.772 & 12.879 & 2.419 \\
\hline $\mathbf{P}_{6}$ & $3.10^{-5}$ & 20.152 & 38.518 & 34.559 & 5.949 & 0.821 \\
\hline $\mathbf{P}_{7}$ & $4.10^{-4}$ & 30.446 & 43.709 & 23.124 & 2.476 & 0.244 \\
\hline $\mathbf{P}_{8}$ & 0.004 & 40.882 & 43.628 & 14.359 & 1.047 & 0.079 \\
\hline $\mathbf{P}_{9}$ & 0.039 & 54.883 & 38.677 & 6.147 & 0.242 & 0.012 \\
\hline $\mathbf{P}_{10}$ & 0.208 & 66.556 & 30.939 & 2.248 & 0.048 & 0.001 \\
\hline $\mathbf{P}_{11}$ & 0.579 & 74.301 & 24.302 & 0.809 & 0.009 & $2.10^{-4}$ \\
\hline $\mathbf{P}_{12}$ & 0.985 & 77.326 & 21.192 & 0.493 & 0.005 & $6.10^{-5}$ \\
\hline $\mathbf{P}_{13}$ & 3.883 & 84.155 & 11.916 & 0.045 & $1.10^{-4}$ & $3.10^{-7}$ \\
\hline $\mathbf{P}_{14}$ & $\begin{array}{l}19.40 \\
7\end{array}$ & 77.515 & 3.078 & $2.10^{-5}$ & 0 & 0 \\
\hline
\end{tabular}

We have made an analysis of the characteristics of the profiles in the SMAF and GIR groups, including the classification status of the patient's dependency.

The first observation on the obtained results is related to the full autonomy of persons. We can observe that the iso-profile 1 of SMAF $\left(\mathrm{P}_{1}\right)$ shows a highest matching with the $\mathrm{GIR}_{5}$ of AGGIR. $P_{1}$ matches GIR $_{5}$ with $43.3 \%$ and matches GIR $_{6}$ with $36.9 \%$. This matching was unexpected based on the results of [18]. The study of the two models enables us to explain this situation. Indeed, the SMAF iso-profile 1 refers to the person's autonomy but with additional services related to supervision and help (e.g., housekeeping, heavy housework and meal preparation). However, the $\mathrm{GIR}_{6}$ refers only to strong autonomy. Therefore, the highest percentage of people -who are classified with the iso-profile 1-, have to be classified into the $\mathrm{GIR}_{5}$ more than in the $\mathrm{GIR}_{6}$. We notice, that the researchers in [18] obtained a perfect match $(100 \%)$ between iso-profile 1 and $\mathrm{GIR}_{6}$, probably due to the small sample used (207 subjects).

The second observation is similar to the previous one but is related to full dependency of persons. Concerning full dependency level, the iso-profile 14 of SMAF $\left(\mathrm{P}_{14}\right)$ did not appear to be the highest level of matching with GIR $_{1}$ (only $19.4 \%$ of matching). Indeed, the highest matching of $\mathrm{P}_{14}$ is observed with $\operatorname{GIR}_{2}$ (77.5\% matching). The same situation is observed for $\mathrm{P}_{11}, \mathrm{P}_{12}$ and $\mathrm{P}_{13}$ where their matching is observed with $\mathrm{GIR}_{2}$ rather than $\mathrm{GIR}_{1}$.

The third observation is related to the SMAF categories (Section $A$ in II). We recall that the iso-profile $\mathrm{P}_{1}, \mathrm{P}_{2}$ and $\mathrm{P}_{3}$ (i.e. category 1) are related to autonomy with some needs of assistance and help as in the AGGIR model with the GIR $_{5}$ and $\mathrm{GIR}_{6}$ groups. Table VII shows that only some percentage of the category 1 is represented by the $\mathrm{GIR}_{5}$ and $\mathrm{GIR}_{6}$. This percentage is exactly equals to $\sum_{i=1}^{3} \sum_{j=5}^{6} M\left[P_{i}, G I R_{j}\right]$ / $\sum_{i=1}^{3} \sum_{j=1}^{6} M\left[P_{i}, G I R_{j}\right]=41.182 \%$. The fourth observation is 
related to dependency described by the category 4 in SMAF (Section $A$ in II) and the GIR $_{1}$ Group in AGGIR. Only a very few percentage of the category 4 is represented by the $\mathrm{GIR}_{1}$ : $\sum_{i=11}^{14} M\left[P_{i}, G I R_{1}\right] / \sum_{i=11}^{14} \sum_{j=1}^{6} M\left[P_{i}, G I R_{j}\right]=0.916 \%$. We notice that the remaining situations (i.e. excluding high levels of autonomy and dependency) are related to motor and mental disabilities (i.e. categories 2 and 3 of SMAF, see section $A$ in II) which correspond to $\mathrm{GIR}_{2}$ to $\mathrm{GIR}_{4}$.

Our simulation of all the possible dependency situations $\left(2.10^{19}\right)$ has revealed some incoherence between the studied models in their evaluation of the required needs and assistance. First, we observe that some persons who are considered in a strong dependency in SMAF with category 4 (i.e. $\mathrm{P}_{11}, \mathrm{P}_{12}, \mathrm{P}_{13}$ and $\mathrm{P}_{14}$ ) have not been classified with $\mathrm{GIR}_{1}$. Consequently, they are not receiving their real required needs since they were classified in groups: $\mathrm{GIR}_{2}$ to $\mathrm{GIR}_{6}$. This percentage is exactly equals to $\sum_{i=11}^{14} \sum_{j=2}^{6} M[P i, G I R j] / 2.10^{19}=0.086 \%$. Similarly, some persons starting to have a decline in their autonomy (i.e. classified from $\mathrm{P}_{4}$ to $\mathrm{P}_{14}$ in SMAF) were considered by AGGIR as autonomous persons (i.e. $\mathrm{GIR}_{1}$ ) hence they will not receive any assistance. The exact amount of this category equals to $\sum_{i=4}^{14} M\left[P_{i}, G_{R} 6\right] / 2.10^{19}=0.679 \%$. Moreover, persons with high levels of autonomy classified with SMAF in category 1 (i.e. $\mathrm{P}_{1}, \mathrm{P}_{2}$ and $\mathrm{P}_{3}$ ) were distributed into the AGGIR's dependency levels from $\mathrm{GIR}_{1}$ to $\mathrm{GIR}_{4}$. Thus, they will receive services and assistance more than their real needs. The exact amount is $\sum_{i=1}^{3} \sum_{j=1}^{4} M\left[P_{i}, G I R_{j}\right] / 2.10^{19}=0.152 \%$.

Our simulation has processed all of the $2.10^{19}$ possible dependency situations. Recall that these situations were obtained by varying the possible evaluations of each activity of daily living (Algorithm 1). The consideration of all the subjects has allowed us to compare the amount of autonomous/dependent persons between SMAF and AGGIR. The number of persons considered as autonomous in SMAF $\left(A_{\mathrm{s}}=0.258 \%\right)$ is less than this number in AGGIR $\left(A_{\mathrm{g}}=5.235 \%\right)$ while the number of dependent persons in SMAF $\left(D_{\mathrm{s}}=0.087 \%\right)$ is more than this number in AGGIR $\left(D_{\mathrm{g}}=0.007 \%\right)$. Indeed, in SMAF (category 1), we have $A_{\mathrm{s}}=\sum_{\mathrm{i}=1}^{3} \sum_{\mathrm{j}=1}^{6} \mathrm{M}\left[\mathrm{P}_{\mathrm{i}}, \mathrm{GIR}_{\mathrm{j}}\right]$ $/ 2.10^{19}=0.258 \%$ while in AGGIR $\left(\mathrm{GIR}_{5}\right.$ and $\left.\mathrm{GIR}_{6}\right)$, we have $A_{\mathrm{g}}=\sum_{i=1}^{14} \sum_{j=5}^{6} M\left[P_{i}, G I R_{j}\right] / 2.10^{19}=5.235 \%$. We have also, in the SMAF category $4, D_{\mathrm{s}}=\sum_{i=11}^{14} \sum_{j=1}^{6} M\left[P_{i}, G I R_{j}\right] / 2.10^{19}=$ $0.087 \%$, while in AGGIR $\left(\mathrm{GIR}_{1}\right)$, we have $D_{\mathrm{g}}=\sum_{i=1}^{14} M\left[P_{i}, G_{R} 1\right] / 2.10^{19}=0.007 \%$. It is noteworthy that in SMAF, a subject has a highest probability to be classified in the profile $\mathrm{P}_{6}$ that is related to persons who need assistance mainly in their mobility activities. The value of this probability is $\sum_{j=1}^{6} M\left[P_{6}, G_{1}\right] / 2.10^{19}=0.37$. In AGGIR, the highest probability $\sum_{i=1}^{14} M\left[P_{i}, G I R 3\right] / 2.10^{19}=0.39$ concerns the group $\mathrm{GIR}_{3}$ that is related to persons who need assistance mainly in mental activities.

We remind that the previous results were obtained using our matching method as presented in Table VI. In our method we have associated the SMAF autonomy scores 0 and -0.5 with the $A$ scoring of AGGIR. In a second simulation, we were interested in refining this approximate association by a new association from SMAF to AGGIR: 0 to $A$ and -0.5 to $B$. Our objective is to reflect the fact that the $A$ evaluation in AGGIR concerns a perfect autonomy in performing a given activity of daily living. The $B$ evaluation is associated to -0.5 because it describes the fact that the person is partially dependent. The results of our second simulation lead us to similar observations as discussed previously but with a significant incoherence in evaluating the dependency of persons. Indeed, we have observed that the degree of dependency in AGGIR was increased for people who are considered as relatively autonomous in SMAF. For instance, we observed a significant drop in the rates of $\mathrm{GIR}_{6}$ and $\mathrm{GIR}_{5}$ (i.e. AGGIR autonomous persons) and high matching $(90.11 \%)$ between autonomous persons in SMAF $\left(\mathrm{P}_{1}\right)$ and persons with more dependency $\left(\mathrm{GIR}_{4}\right)$.

\section{DISCUSSION}

The main goal of this work targets a better understanding about the context of persons in order to provide them with eHealth services that meet their context and real needs (Fig 1.). In order to reach this objective, we need to consider the most important person's activities, which affect the performance of the individual in negative and positive situations. Therefore, an ideal platform that provides such eHealth services should consider the most important activities for monitoring and evaluation. Our work has considered current models, used by the health domain, to evaluate the execution of human activities. This will help to gain a better knowledge about the medical evaluation tools and highlight their drawbacks in order to provide new eHealth ecosystems easily adaptable to health institutions. To the best of our knowledge, this is the largest and most complete study that considers the two mostly used models in the evaluation of activity of daily living. The work in [18] has performed a similar comparison but only with a limited set of subjects. This limited set had not permitted to gain a complete vision about the limitations and incoherence of existing models.

Our complete simulation (20 trillion of possible evaluations) has lead us to observe that in general, uneven distribution has appeared from the two studied dependency models with some incoherence in the evaluation of subjects' dependency. Our results have shown that the AGGIR model is not as comprehensive as SMAF, this is clearly shown in:

- Mismatch in levels of autonomy and dependency from AGGIR to SMAF.

- Distribution from autonomy evaluation in AGGIR to dependency in SMAF, on the contrary distribution from dependency in AGGIR to autonomy in SMAF.

- Finally, AGGIR is not covering all the important functions that show the real performance of the individual achieving their daily tasks.

On the other hand, although SMAF covers multiple activities, it has shown weaknesses in some aspects. It lacks validity periods regarding the activities' evaluations and exaggerates by considering some activities in situations of severe dependency.

In the ecosystem of eHealth services, linking validity periods to each monitored activity is of high importance while 
providing context-aware services. Indeed, in order to ensure efficient services in time, the validity should be dependent on the type of activity and the necessity of updates with a welldetermined threshold. For optimizing eHealth platforms, some activities have not to be monitored or measure all the time. For instance, in severe dependency levels it is not necessary to monitor the grooming activity all time by models and platforms. This improves the architecture to sense some activities, which directly affect the lives of the elderly. Consequently, we have to monitor only appropriate activities that could trigger some services.

Finally, in the context of eHealth services, our simulations led us to realize that the existing models are inadequate and not efficient to give an accurate assessment about the elderly dependency. Indeed, the existing models do not reflect the real context of the person. As we have shown previously, the same subject can be considered as autonomous by using one model and seen to be a dependent person in another model.

\section{CONCLUSION}

In this paper, we considered the monitored person's context by studying and comparing the existing health models used in the evaluation of dependent people. We focus on accurately meeting the needs of dependent people for appropriate healthcare services. Our study has clearly shown neither SMAF nor AGGIR models could fulfill the requirements of efficiency and reliability of eHealth platforms services. Therefore, in order to further reduce the error rate in the existing evaluation models and to build efficient eHealth ecosystems, we should improve the performance of evaluation models. According to our experimentations and proposed matching algorithm, SMAF provides a better knowledge than AGGIR regarding the evaluation of patients' needs of help and assistance. Covering most important daily activities is important; however SMAFlike models need improvements in order to be adopted in eHealth new platforms which accommodate both efficiency and reliability. Such improvements concern for instance: the linking of evaluations to validity periods, the consideration of a sub set of activities that depend on the situation (context) of persons, the determination of the required frequency to evaluate (sense) the activities, etc. Next steps will be enriching the SMAF model and make it ready to be included in our targeted context-aware eHealth architecture that provides eHealth services at home. We will consider the compatibility with heterogeneous data sources and sensors on one hand and with heterogeneous patient profiles on the other hand.

\section{REFERENCES}

[1] United Nations, Department of Economic and Social Affairs, http://esa.un.org/unpd/wpp/, acceded March 2014.

[2] AGGIR (Autonomy Gerontology Iso-Resources Group) model. "The national standardized instrument determining the attribution of the specific dependence allowance in France," Minist. for Labour, Social Relations, the Family and Solidarity, Dec- 2008-821 (update of Dec2001-1084), Official J. of the French Gov.: JO of 21 august 2008.
[3] R. Hébert, R. Carrier and A. Bilodeau, "The functional autonomy measurement system (SMAF): Description and validation of an instrument for the measurement of handicaps," Age ageing, vol.17, issue 5, pp. 293-302, Septemper 1988.

[4] T. Lemlouma, S. Laborie and P. Roose, "Toward a Context-Aware and Automatic Evaluation of Elderly Dependency in Smart Homes and Cities," Fourteenth IEEE International Symposium on a World of Wireless Mobile and Multimedia Networks (WoWMoM'13), Madrid, Spain, July 2013.

[5] S. Katz, A.B. Ford, R.W. Moskowitz, B.A. Jackson and M.W. Jaffe. "Studies of illness in the aged: The Index of ADL, a standardized measure of biological and psychosocial function," Vol.185 pp. 914-919, Septemper 1963.

[6] M. Lawton and E. Brody, "Assessment of older people: Self maintaining and instrumental activities of daily living," Gerontologist, vol. 9, pp. 179-186, 1969.

[7] N. Dubuc, R Hébert, J. Desrosiers, M. Buteau and L. Trottier, "Disability-based classification system for older people in integrated long-term care services: The Iso-SMAF profiles," Elsevier Science, Archives of Gerontology and Geriatrics, vol. 42, pp.191-206, 2006.

[8] M. Stineman, C.J. Tassoni, J.J. Escarce et al. "Development of FunctionRelated Groups Version 2.0: A Classification System for Medical Rehabilitation," Health Services Research 32:4, Vol. 32, No. 4, pp. 529548, October 1997.

[9] D. Scheller-Kreinsen, W. Quentin and R Busse, " DRG-Based Hospital Payment Systems and Technological Innovation in 12 European Countries," Elsevier Science, vol. 14, pp. 1166-1172, July 2011.

[10] X.H Binh, M.D Mascolo, A. Gouin and N. Noury, "Health Smart Home - Towards an assistant tool for automatic assessment of the dependence of elders," IEEE Engineering in Medicine and Biology Society, Lyon, pp. 3806-3809, doi:10.1109/IEMBS.2007.4353161, August 2007.

[11] C. Franco, J. Demongeot, C. Villemazet and N. Vuillerme, "Behavioral Telemonitoring of the Elderly at Home: Detection of Nycthemeral Rhythms Drifts from Location Data," In Proc. of the 24th IEEE International Conference on Advanced Information Networking and Applications Workshops (WAINA), Perth, WA, pp. 759-766m, doi: 10.1109/WAINA.2010.81, April 2010

[12] J. Rantz Marilyn J. et al. "Automated technology to speed recognition of signs of illness in older adults," J. of Gerontological Nursing, Vol. 38(4): pp. 18-23, doi:10.3928/00989134-20120307-01, April 2012.

[13] R. Hébert, J. Guilbeault, J. Desrosiers and N. Dubuc, "The Functional Autonomy Measurement System (SMAF): a clinical-based instrument for measuring disabilities and handicaps in older people," Geriatrics Today: J Can Geriatrics Soc, vol.4, pp.141-147, September 2001.

[14] J. Desrosiers, A. Rochette, L. Noreau, G. Bravo, R. Hébert and C. Boutin, "Comparison of two functional independence scales with a participation measure in post-stroke rehabilitation," Elsevier Science, doi:10.1016/S0167-4943(03)00044-X,vol. 37, pp. 157_/172, April 2003.

[15] Measuring Health: A Guide to Rating Scales and Questionnaires, Measuring Health, Ian McDowell, Oxford University Press, Third Edition, 2006

[16] R. Hébert, M. Raiche and R. Gueye, "Survey disability questionnaire does not generate valid accurate data compared to clinical assessment on an older population," Elsevier Science, Archives of Gerontology and Geriatrics, vol. 54, pp. e57-e62, 2012

[17] M. Raiche, R. Hébert, M. Dubois, R. Gueye and N. Dubuc, "Yearly transitions of disability profiles in older people living at home," Elsevier Science, Archives of Gerontology and Geriatrics, vol. 55, pp. 399-405, 2012.

[18] P. Gervais. "Classification Des Personnes Âgées En Perte D'autonomie Fonctionnelle : Comparaison Des Profils Iso-Smaf Aux Groupes IsoRessources Issus De La Grille Aggir," Cairn.info, ISSN 1768-5958, no. 26, page 205 to $218,2009$. 